\title{
ACTUAL USAGE PENGGUNAAN E-LEARNING DENGAN TECHNOLOGY ACCEPTANCE MODEL (TAM)
}

\author{
Riski Nurida Rahmawati *, I Made Narsa \\ Universitas Airlangga, Jl. Airlangga no. 4-6, Gubeng, Surabaya 60115, Indonesia \\ * Corresponding Author. Email: riskinurida@gmail.com \\ Received: 7 October 2019; Revised: 15 October 2019; Accepted: 16 October 2019
}

\begin{abstract}
Abstrak
Kemajuan dalam teknologi informasi memberi kesempatan pada institusi pendidikan untuk mengadopsi teknologi untuk meningkatkan efisiensi pembelajaran. e-learning merupakan salah satu pengembangan tersebut dan tidak dapat disampaikan tanpa menggunakan teknologi. Tujuan penelitian ini yaitu untuk mendapatkan bukti empiris terkait actual usage dari penggunaan e-learning dengan pemediasi intention to use. Data dalam penelitian ini sebanyak 135 kuesioner yang disebarkan kepada mahasiswa Universitas Airlangga yang sempat memanfaatkan AULA. AULA merupakan portal e-learning di Universitas Airlangga, yang merupakan singkatan dari Airlangga Univeristy e-learning Application. Alat uji yang digunakan adalah Warp PLS. Perceived usefulness yang dirasakan pada penggunaan e-learning tidak memberikan pengaruh pada actual usage. Perceived ease of use memiliki hubungan signifikan pada intention to use. Hasil pengujian pengaruh tidak langsung menunjukkan perceived usefulness mempengaruhi niat perilaku untuk menggunakan teknologi. Persepsi kemudahan menggunakan teknologi dimotivasi tingkat kepercayaan individu terhadap kemampuan menggunakan teknologi, yang mana akan mendorong persepsi kebermanfaatan dan berimplikasi pada niat untuk menggunakan teknologi untuk menggunakan e-learning.
\end{abstract}

Kata kunci: Actual Usage, Perceived Ease of Use, e-learning, Intention to use

\section{ACTUAL USAGE USE OF E-LEARNING WITH TECHNOLOGY ACCEPTANCE MODEL (TAM)}

\begin{abstract}
Progress in information technology provides opportunities for education to encourage technology to improve learning efficiency. E-learning is one such development and cannot be delivered without using technology. The purpose of the study is to get empirical evidence related to actual usage of using e-learning with intention to use as a mediation. Data used in the study were 135 questionnaires that distributed to students of Airlangga University who are active or have used / participated in AULA (Airlangga University e-learning Application). AULA is an e-learning portal at Airlangga University. Data analysis techniques using Warp PLS. The results show the perceived usefulness of e-learning, does not affect the actual use. Perceived ease of use has a significant positive relationship with intention to use. The results evaluation direct effect of perceived usefulness influences intention to use technology. Perceived ease of use of technology is motivated by the level of individual trust in ability to use technology, which will encourage perceptions of usefulness and have implications for the intention to use technology to use e-learning.
\end{abstract}

Keywords: Actual Usage, Perceived Ease of Use, e-learning, Intention to use

doi) http://dx.doi.org/10.21831/jitp.v6i2.26232 


\section{Pendahuluan}

Pesatnya arus sistem dan teknologi informasi mengubah cara pandang orang atas informasi yang tidak terbatas pada media cetak ataupun televisi, namun juga melalui internet yang cakupannya lebih luas. Hal tersebut tentunya mempengaruhi aktivitas keseharian. Perubahan berbagai aspek kehidupan ini didukung beberapa faktor yang kompleks menimbulkan sebuah tuntutan dalam kualitas pendidikan agar lebih memadai dalam menghadapi berbagai perkembangan. Adanya kualitas dan kinerja yang tinggi dimotivasi ICT (Information Communication Technology) serta nilai adalah kesatuan, saling terhubung dengan baik dalam sistem pembelajaran (Setiawan, Hana, \& Waslaludin, 2014). Mutu pendidikan harus menyesuaikan dengan perkembangan teknologi, dimana IT dan komunikasi telah banyak berperan didalamnya (Folden, 2012).

Perkembangan teknologi multimedia dapat merubah cara seseorang untuk mendapatkan dan menyesuaikan informasi. Multimedia juga berpotensi bagi pengajar atau dosen sebagai pengembangan teknik pengajaran. Demikian pula dari segi murid atau mahasiswa, kemudahan dalam mengakses dan mendapatkan informasi diharapkan terjangkau dengan adanya multimedia (Hussein, 2017). Kemampuan multimedia yang terkoneksi dengan internet semakin mempermudah mendapatkan informasi dalam kegiatan belajar-mengajar (AlAzawei, Patrick, \& Lundqvist, 2017). Dari segi dunia pendidikan, adanya perubahan tersebut memberikan manfaat penting (Baleghi-Zadeh, Ayub, Mahmud, \& Daud, 2017). Adanya e-learning membantu proses pembelajaran tanpa perlu interaksi secara langsung antara dosen atau pengajar dengan mahasiswa, sehingga efek-tivitas belajar dapat lebih ditingkatkan dengan adanya forum tanya jawab dan kemudahan akses materi belajar (Hussein, 2017).

E-learning merupakan sebuah metode pembelajaran yang menggunakan media elektronik atau device tertentu sebagai pe- rantara untuk menyampaikan materi pembelajaran. E-learning pada umumnya merupakan website dimana user saling berinteraksi satu sama lain layaknya situs media sosial. Proses pembelajaran mencakup penyampaian bahan belajar, interaksi pembelajaran serta evaluasi pembelajaran (Priyadi et al., 2013, p. 141). Dikatakan sebagian besar proses karena ada proses yang tidak dilakukan secara online, misalnya kegiatan tatap muka untuk belajar menggunakan komputer untuk komunikasi. Menurut Kusmana (2017), walaupun pemanfaatan internet untuk proses belajar mengajar melalui e-learning sangat banyak dan lebih memberikan kesan fleksibel, terdapat beberapa kekurangan. Kurangnya interaksi secara langsung antara mahasiswa dengan dosen sebagai pengajar dapat menghambat terbentuknya nilai dalam kegiatan belajar mengajar.

Perkembangan e-learning ini juga menjadi pilihan karena adanya tuntutan perubahan. Berbagai macam implementasi e-learning baik berupa materi dalam web server hingga model terpadu dengan bermacam-macam objek pembelajaran lengkap dengan multimedia serta tautan ke perpustakaan, kursus yang diikuti, komunikasi diskusi dan berbagai educational tools lainnya (Silva, Silva, Chan, 2019). Pada era tekno-logi saat ini, mahasiswa Universitas Airlangga merupakan individu yang mempunyai dayaguna dalam penguasaan komputer atau memiliki literasi komputer yang bagus. Walaupun pihak universitas sudah memberikan wadah melalui portal $e$ learning, kenyataannya bahwa belum semua pengajar atau dosen menggunakan media $e$ learning dalam kegiatan belajar mengajar. Secara tidak langsung, pengajar atau dosen merupakan salah satu motivasi maha-siswa dalam menggunakan atau menmanfaatkan e-learning. Tidak semua mata kuliah yang diberikan dapat diakses di portal e-lerning. Penggunaan e-learning bisa berupa akses materi pembelajaran, forum diskusi/ tanya jawab, bahkan pengerjaan ujian.

Dalam bidang pendidikan, jumlah studi menggunakan Technology Acceptance 
Model (TAM) untuk menyelidiki proses adopsi teknologi terus meningkat (SánchezPrieto, Olmos-Migueláñez, \& GarcíaPeñalvo, 2017). TAM dianggap berpengaruh dan dapat menjelaskan penerimaan seseorang dalam pendayagunaan suatu sistem informasi (Jogiyanto, 2008, p. 111). Model TAM ini adaptasi dari model Theory of Reasoned Action (TRA) oleh Fishbein dan Ajzen, dimana terdapat dua konstruk utama, yaitu: kegunaan (perceived usefulness / $P U)$ dan kemudahan dalam peng-gunaan (perceived ease of use/ PEU) (Sánchez-Prieto, Olmos-Migueláñez, \& García-Peñalvo, 2017). Konstruk kegunaan merupakan suatu keadaan dimana seseorang memercayai jika menggunakan sistem dapat meningkatkan kinerja mereka. Sedangkan konstruk kemudahan penggunaan adalah keadaan ketika indi-vidu percaya bahwa tidak diperlukan usaha keras dalam menggunakan sistem (Davis, 1985). TAM dianggap paling tepat menurut banyak peneliti dalam menentukan kesiapan kelompok untuk menjalankan teknologi computer basic pada aktivitasnya (Alomary \& Woollard (2015); Baziad (2015)).

Kegunaan dan kebermanfaatan $e$ learning dapat dirasakan oleh mahasiswa yang dipicu oleh PU. Persepsi kegunaan individu pengguna ini dapat lebih didorong oleh adanya kemudahan (fleksibilitas) dalam penggunaan e-learning. Hal ini akan menghilangkan keengganan bagi setiap pengguna (dalam hal ini mahasiswa) agar cenderung sering mengakses e-learning. Adanya alat atau sistem yang lebih mudah untuk digunakan akan mendorong keyakinan diri individu untuk menggunakannya (Smet, Burgonjon, Wever, Schellens, \& Valcke, 2012). Hal ini dapat terjadi apabila dalam diri mahasiswa dapat memandang produk e-learning memiliki kegunaan yang besar dalam perkuliahan yang dijalankan oleh mahasiswa. Tingkat kepercayaan dalam meningkatkan capaian pembelajaran dapat mempengaruhi intensitas penggunaan e-learning (Harris, 2017).

Keinginan untuk menggunakan teknologi dapat dibentuk atau dimotivasi oleh PU. Fadare (2015) menyatakan bahwa tingkat kepercayaan seseorang mengenai apakah suatu aplikasi dapat membantu pekerjaan lebih baik atau tidak akan memengaruhi preferensi dalam menggunakan atau tidak menggunakan aplikasi tersebut. Konstruk PEU adalah taraf dimana individu mempercayai bahwa penggunaan sistem akan mudah dalam penerapannya (Nursiah, 2018). Semakin besarnya niat seseorang dalam menerapkan teknologi bergantung pada tingkat kemudahan teknologi untuk dapat digunakan (Barhoumi, 2016; Khan \& Woosley, 2019).

PEU memengaruhi konstruk kegunaan, sikap, intensi dan penggunaan teknologi sesungguhnya. Namun yang paling signifikan adalah pengaruh ke konstruk kegunaan, sementara terhadap konstruk lain pengaruhnya tidak signifikan (Jogiyanto, 2008, p. 115). Terdapat 6 indikator untuk mengukur konstruk ini, yaitu: kemudahan sistem untuk dipelajari (easy of learn), kemudahan sIstem untuk dikontrol (controllable), interaksi dengan system yang mudah dipahami dan jelas (clear and understandable), fleksibilitas interaksi (flexibility), mudah untuk terampil menggunakan system (easy to become skillful) dan mudah digunakan (easy to use) (Davis, 1989). Selain itu, persepsi akan kemudahan dalam proses penggunaan menjadi sebuah dorongan bagi mahasiswa untuk lebih sering dalam menggunakan produk $e$ learning yang dibuat oleh pihak Universitas, sehingga untuk penggunaan (actual usage) produk e-learning menjadi lebih sering dilakukan oleh mahasiswa. Berdasarkan penjabaran latarbelakang sebelumnya, peneliti akan mengkaji mengenai actual usage penggunaan e-learning dengan intention to use sebagai variabel mediasi di Universitas Airlangga, Jl. Airlangga no. 4-6, Surabaya, Indonesia.

Metode Penelitian

J Sampel yang digunakan yaitu mahasiswa yang pernah menggunakan $e$ learning di Universitas Airlangga. Alasan 
pemilihan objek adalah karena Universitas Airlangga memiliki situs e-learning sebagai penunjang dalam kegiatan belajar mengajar, dan sudah berjalan walaupun belum semua matakuliah menerapkannya. Sebanyak 135 kuesioner disebar melalui google form bagi mahasiswa yang sudah memakai AULA (Airlangga Univeristy e-learning Application). AULA ini merupakan nama $e$ learning Universitas Airlangga, dimana terhubung dengan akun individu.

Variabel independen penelitian ada dua yaitu: perceived usefulness dan perceived ease of use, dimana pengukuran keduanya mengacu pada kuesioner pengembangan dari Davis (1985). Variabel mediasi model penelitian ini intention to use. Pengu-kuran intention to use mengacu pada kuesioner Wang (2009). Variabel dependen actual usage mengacu pada kuesioner yang dikembangkan oleh Davis (1985). Keseluruhan variabel diukur menggunakan kuesioner skala likert 5 poin, dimana termasuk dalam kategori sangat tidak setuju (1) sampai dengan sangat setuju (5).

Penelitian ini difokuskan pada topik terkait dengan tingkat penerimaan $e$ learning. Untuk menganalisis penerimaan $e$ learning bagi mahasiswa dibutuhkan metode khusus dalam menganaliisa sistem. Metode yang digunakan adalah model TAM, dimana dianggap berpengaruh dan dapat menjelaskan penerimaan seseorang dalam penggunaan sistem informasi (Jogiyanto, 2008, p. 111). Model penelitian yang digunakan dapat dilihat pada Gambar 1.

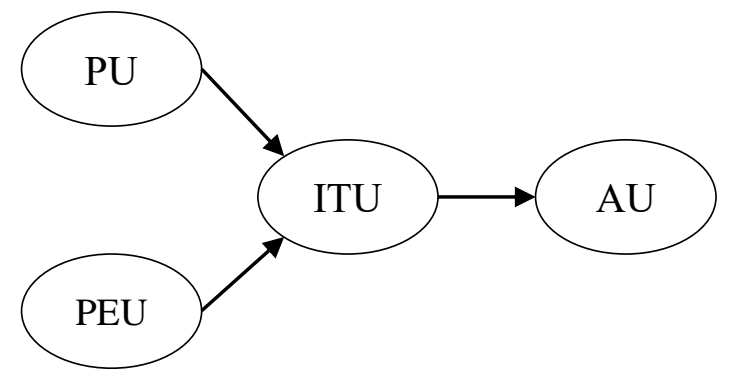

Gambar 1. Kerangka Konseptual

Sumber: Data olahan peneliti, 2018
Keterangan:

PU : Perceived Usefulness

PEU : Perceived Ease of Use

ITU : Intention to Use

AU : Actual Usage

\section{Hasil dan Pembahasan}

Berkaitan penerimaan e-learning, peneliti ingin melihat apakah intention to use menjadikan mahasiswa lebih bersedia menggunakan e-learning. Berikut merupakan hasil uji dan pembahasan penelitian ini:

Demografi Responden

Tabel 1. Demografi Responden

\begin{tabular}{llc}
\hline \multicolumn{1}{c}{ Keterangan } & Kategori & Jumlah \\
\hline Gender & Pria & 44 \\
& Wanita & 91 \\
Pendidikan saat ini & D3 & 7 \\
& S1 & 99 \\
& S2 & 28 \\
Skses internet di & Tidak & 17 \\
rumah & Ya & 118 \\
Pengalaman & $1-3$ & 6 \\
menggunakan internet & tahun & \\
& $4-6$ & 23 \\
& tahun & $7-10$ \\
& tahun & 58 \\
& $>10$ & 48 \\
& tahun & \\
\hline
\end{tabular}

Sumber: Data olahan peneliti, 2018

Total responden sebanyak 135 orang, terdiri dari 91 orang perempuan dan 44 orang laki-laki. Dilihat dari segi pendidikan, kebanyakan responden berasal dari mahasiswa S1. Untuk jumlah mahasiswa S1 memang lebih banyak dibandingkan dengan jenjang yang lainnya, karena di Universitas Airlangga terdapat beberapa jurusan yang notabene adalah mahasiswa jenjang S1. Perkembangan teknologi saat ini semakin memudahkan akses internet dimanapun dan kapanpun. Akses internet bisa didapatkan melalui wifi 
ataupun melalui koneksi dari smartphone atau yang biasa disebut dengan tathering. Jika dilihat dari pengalaman menggunakan internet, mayoritas memiliki pengalaman dalam jangka waktu yang lama, yakni 7-10 tahun. Tentunya dengan lama pengalaman tersebut dapat disimpulkan bahwa penggunaan internet ini sangat melekat dalam keseharian manusia sejak lama. Internet telah membantu meringankan aktivitas ditengah kesibukan yang dilakukan. Berbagai kemudahan yang ditawarkan pun tentunya memberi banyak sekali manfaat bagi penggunanya apabila digunakan dengan bijak.

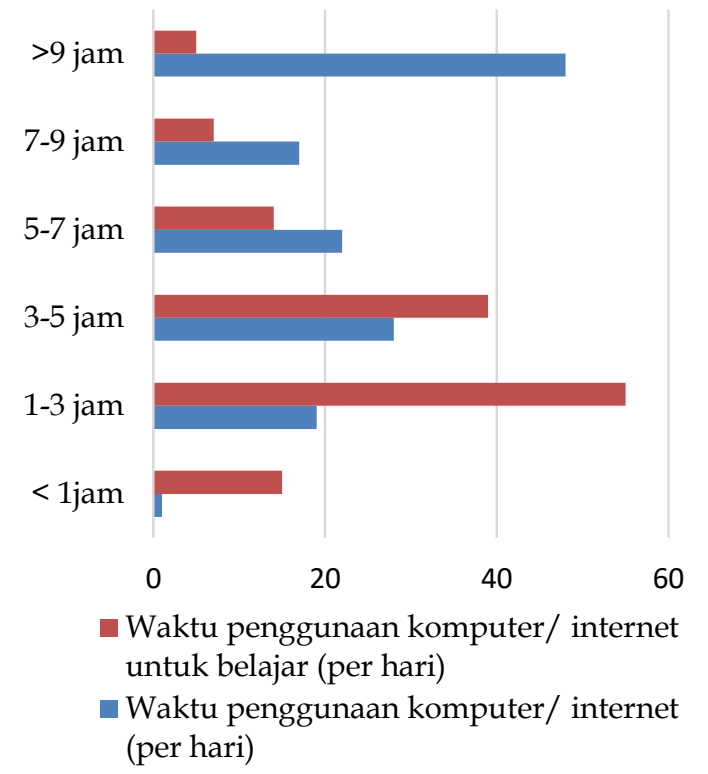

Sumber: Data olahan peneliti, 2018

\section{Gambar 2. Waktu Penggunaan Komputer/ Internet}

Jika dilihat pada gambar 2, penggunaan internet atau komputer tidak terbatas hanya untuk komunikasi di media sosial, update informasi ataupun berita saja. Penggunaan teknologi saat ini juga dapat digunakan sebagai penunjang dalam kegiatan belajar mengajar. Tidak sedikit individu yang meluangkan banyak waktunya untuk belajar melalui kecanggihan teknologi informasi yang ada saat ini. Dengan adanya fleksibilitas dan kemajuan teknologi yang ada ini semakin memudahkan pengguna, dan tidak dipungkiri dalam kese- harian sangat erat kaitannya dengan penggunaan internet atau komputer sebagai penunjang aktivitas, sehingga intensitas penggunaannya semakin bertambah.

Outer Loading, Reliability Coefficient, Average Variances Extracted dan Evaluasi Penilaian Model

Tabel 2. Outer Loading, Reliability Coefficient dan Average Variances Extracted

\begin{tabular}{cccc}
\hline & Outer Loading & Reliability & AVE \\
\hline PU1 & 0,682 & & \\
PU2 & 0,696 & 0,815 & 0,526 \\
PU3 & 0,753 & & \\
PU4 & 0,765 & & \\
PEU1 & 0,799 & & \\
PEU2 & 0,876 & 0,913 & 0,725 \\
PEU3 & 0,873 & & \\
PEU4 & 0,856 & & \\
AU1 & 0,884 & 0,874 & 0,776 \\
AU2 & 0,884 & & \\
ITU1 & 0,881 & 0,877 & 0,781 \\
ITU2 & 0,881 & & \\
Sumber: Data olahan peneliti, 2018 &
\end{tabular}

Nilai outer loading untuk variabel perceived usefulness yang paling besar adalah PU4 $(0,765)$. Variabel PEU juga memiliki nilai outer loading yang paling besar yaitu pada PEU2 $(0,876)$. Nilai outer loading untuk variabel actual usage yang terbesar adalah pada AU1 $(0,884)$. Sementara itu, untuk variabel intention to use nilai outer loading yang terbesar adalah 0,881 . Hasil dari tabel 2 terlihat seluruh indikator mempunyai nilai outer loading factor $>0,5$. Hal ini berarti indikator sudah layak untuk mereferensikan variabel, indikator-indikator tersebut telah memenuhi convergent validity. Berdasarkan tabel Average Variances Extracted (AVE), menunjukan nilai AVE setiap variabel dari konstruk tersebut $>0,5$, maka menunjukkan setiap variabel dari penelitian memenuhi validitas diskriminan. Jika dilihat dari nilai composite reliability coefficient, menunjukkan bahwa dari masing-masing variabel PU $(0,815)$, PEU $(0,913)$, AU $(0,874)$ dan ITU $(0,877)$ penelitian sudah memenuhi rule of thumb. 
Tabel 3. Evaluasi Goodness of Fit Model

\begin{tabular}{|c|c|c|c|}
\hline Pengukuran & Parameter & Hasil & Ket \\
\hline $\begin{array}{l}\text { Average Path } \\
\text { Coefficien }\end{array}$ & $p<0.05$ & $\begin{array}{c}0.453 \\
p< \\
0,001\end{array}$ & $\begin{array}{l}\text { Memenuhi } \\
\text { kriteria }\end{array}$ \\
\hline $\begin{array}{l}\text { Average } \quad R \text { - } \\
\text { squared }\end{array}$ & $\mathrm{p}<0.05$ & $\begin{array}{c}0.402, \\
p< \\
0,001\end{array}$ & $\begin{array}{l}\text { Memenuhi } \\
\text { kriteria }\end{array}$ \\
\hline $\begin{array}{l}\text { Average } \\
\text { Adjusted R- } \\
\text { squared }\end{array}$ & $\mathrm{p}<0.05$ & $\begin{array}{c}0.395 \\
\mathrm{p}< \\
0,001\end{array}$ & $\begin{array}{l}\text { Memenuhi } \\
\text { kriteria }\end{array}$ \\
\hline Average VIF & $\geq 3,3$ & 1,965 & $\begin{array}{l}\text { Memenuhi } \\
\text { kriteria }\end{array}$ \\
\hline $\begin{array}{l}\text { Average Full } \\
\text { Collinearity } \\
\text { VIF }\end{array}$ & $\geq 3,3$ & 2,292 & $\begin{array}{l}\text { Memenuhi } \\
\text { kriteria }\end{array}$ \\
\hline $\begin{array}{l}\text { Tenenhaus } \\
\text { GoF }\end{array}$ & $\begin{array}{c}\text { Small } \geq 0,1 ; \\
\text { medium } \geq \\
0,25 ; \text { large } \geq \\
0,36\end{array}$ & 0,531 & Large \\
\hline $\begin{array}{l}\text { Sympson's } \\
\text { Paradox Ratio }\end{array}$ & $=1$ & 1 & $\begin{array}{l}\text { Memenuhi } \\
\text { kriteria }\end{array}$ \\
\hline $\begin{array}{l}\text { R-squared } \\
\text { Contribution } \\
\text { Ratio }\end{array}$ & $=1$ & 1 & $\begin{array}{l}\text { Memenuhi } \\
\text { kriteria }\end{array}$ \\
\hline $\begin{array}{l}\text { Statistical } \\
\text { Suppression } \\
\text { Ratio }\end{array}$ & $\geq 0,7$ & 1 & $\begin{array}{l}\text { Memenuhi } \\
\text { kriteria }\end{array}$ \\
\hline $\begin{array}{l}\text { Nonlinear } \\
\text { Bivariate } \\
\text { Causality } \\
\text { Direction } \\
\text { Ratio } \\
\end{array}$ & $\geq 0,7$ & 1 & $\begin{array}{l}\text { Memenuhi } \\
\text { kriteria }\end{array}$ \\
\hline
\end{tabular}

Sumber: Data olahan peneliti, 2018

Seluruh variabel memiliki realibility yang tinggi, dimana hal ini dapat dilihat dari seluruh nilai composite realibility tersebut lebih besar $>0.7$. Hasil menunjukan bahwa model dalam penelitian reliable. Dapat disimpulkan bahwa seluruh variabel dalam penelitian ini reliabel dan dapat diandalkan untuk digunakan dalam analisis lebih lanjut.

Nilai $r$-square intention to use sebesar 0,684 . Hal ini menunjukkan variabilitas konstruk intention to use dijelaskan oleh PU dan PEU sebesar 68,4\%, sisanya 31,6\% dijelaskan variabel lain. Konstruk tingkat actual usage memiliki nilai $\mathrm{R}^{2}$ sebesar 0,593. Hal ini menunjukkan bahwa besarnya presentase actual usage dapat dijelaskan sebesar $59,3 \%$ oleh intention to use, sisanya $40,7 \%$ dijelaskan oleh variabel lain diluar penelitian. Evaluasi model struktural dilakukan dengan evaluasi goodness of fit (GoF) dapat dilihat pada Tabel 3 .

Hasil evaluasi Goodness of Fit model (GoF) berdasarkan melalui 10 pengukuran model secara keseluruhan menunjukkan model penelitian ini memiliki model yang fit.

Uji hipotesis

Hasil output dari uji mediasi yang dilakukan dapat dilihat pada Tabel 4.

Tabel 4. Uji Hipotesis Pengaruh Langsung

\begin{tabular}{ccccc}
\hline Hipotesis & Pengaruh & $\begin{array}{c}\text { Path } \\
\text { Coeffi } \\
\text { cient }\end{array}$ & $\begin{array}{c}P \\
\text { Values }\end{array}$ \\
\hline $\mathrm{H} 1$ & PU $\rightarrow$ ITU & 0,115 & 0,086 \\
H2 & PEU $\rightarrow$ ITU & 0,198 & 0,009 \\
H3 & ITU $\rightarrow$ AU & 0,770 & $<0,001$ \\
\hline
\end{tabular}

Sumber: Data olahan peneliti, 2018

Hasil dari tabel uji hipotesis pengaruh langsung pada tabel 4, jika dilihat dari path coefficient menunjukkan bahwa pengaruh langsung antara PU terhadap ITU berpengaruh lemah, yang ditunjukkan dari p-value sebesar 0,086, sehingga dapat dikatakan tidak signifikan. Namun, nilai path coefficient dari perceived usefulness menujukan hasil positif sebesar 0,115 terhadap intention to use. Angka path coefficient menunjukkan jika terjadi peningkatan pada PU sebanyak satu, maka ITU naik 0,115. Sebaliknya, adanya penurunan PU sebanyak satu, maka ITU turun 0,115. Dapat disimpulkan H1 tidak dapat diterima, dimana percieved usefulness tidak signifikan positif terhadap actual usage.

Hasil tersebut memperlihatkan persepsi kebermanfaatan pada e-learning tidak akan memiliki pengaruh pada tingkat penggunaan. Hal ini mungkin disebabkan oleh adanya faktor lain yang mempengaruhi, faktor lain tersebut seperti adanya peran pengajar/ dosen. Ada mahasiswa yang beranggapan bahwa penggunaan e-learning hanya sekedar untuk memenuhi tugas dari dosen saja. Selebihnya mahasiswa tidak akan menggunakan e-learning. Adanya tuntutan dari dosen untuk menggunakan $e^{-}$ 
learning sebagai sarana belajar-mengajar membuat mahasiswa mau tidak mau harus menggunakan e-learning dalam mata kuliah yang ditempuhnya. Hal ini juga dapat dikaitkan dengan pengalaman mahasiswa atau sifat dari teknologi pembelajaran.

Hasil untuk pengujian hipotesis 1 (H1) tidak sejalan dengan penelitian Cakır dan Solak (2015); Handayani dan Harsono (2016); Nursiah (2018) , dimana PU memiliki dampak signifikan pada kedua niat dalam menggunakan. Hasil penelitian ini sejalan dengan penelitian Rahmawati dan Narsa (2019). Penelitian Chang dkk. (2005) menemukan bahwa disaat pengalaman yang dimiliki oleh pegguna sangat minim terhadap sistem informasi, biasanya pengguna cenderung memfokuskan pada kemudahan implementasinya. Hal ini tentunya akan berbeda jika jam terbang dalam penggunaan sistem sudah banyak, pengguna akan lebih fokus pada kebermanfaatannya. Sehingga, untuk first impression kemudahan oleh pengguna akan lebih membuka jalan untuk keputusan penggunaan kedepannya. Sebagai nilai tambah, kebermanfaatan sistem yang dirasa berguna akan membuat pengguna pada akhirnya menerima sistem tersebut.

Hubungan langsung antara PEU terhadap actual usage menunjukan nilai $p$ value sebesar 0,009 dimana $<0,05$ sehingga menunjukkan hubungan yang signifikan. Path coefficients dari hubungan tersebut adalah sebesar 0,198 yang berarti terdapat hubungan positif antara PEU dengan behavioral intetntion. Angka path coefficient menunjukkan jika terjadi peningkatan pada PEU, maka konstruk intention to use naik sebanyak 0,198 begitu juga sebaliknya. Dengan demikian hipotesis 2 (H2) diterima. Hasil dari pengujian hipotesis 2 (H2) menunjukkan bahwa PEU berpengaruh signifikan positif terhadap ITU. Hasil pengujian H2 sejalan dengan penelitian Cakır dan Solak (2015); Handayani dan Harsono (2016); Nursiah (2018); Rahmawati dan Narsa (2019).

Persepsi kemudahan menggunakan teknologi dimotivasi taraf kepercayaan pengguna bahwasannya mereka berkemampuan dalam menggunakan teknologi, yang ditunjukkan dalam hasil pengujian $\mathrm{H} 3$, sehingga PEU dalam menggunakan teknologi memacu PU yang akan mempengaruhi niat menggunakan e-learning. Hubungan langsung antara intention to use terhadap actual usage menunjukan nilai $p$ value sebesar <0,001, dimana $>0,05$ sehingga menunjukkan hubungan signifikan. Path coefficients dari hubungan tersebut adalah sebesar 0,770 yang berarti terdapat hubungan positif antara intention to use dengan actual usage. Dengan demikian hipotesis (H7) dapat diterima.

Tabel 5. Uji Hipotesis Pengaruh Tidak Langsung

\begin{tabular}{clc}
\hline Hipotesis & \multicolumn{1}{c}{ Pengaruh } & $V A F$ \\
\hline $\mathrm{H} 4$ & $\mathrm{PU} \longrightarrow \mathrm{ITU} \longrightarrow \mathrm{AU}$ & $61,6 \%$ \\
$\mathrm{H} 5$ & $\mathrm{PEU} \longrightarrow \mathrm{ITU} \longrightarrow \mathrm{AU}$ & $41,019 \%$ \\
\hline
\end{tabular}

Sumber: Data olahan peneliti, 2018

Untuk melakukan pengujian mediasi SEM-PLS digunakan dengan metode Variance Acounted For (VAF) model dan formula sebagai berikut:

$$
\text { VAF }=\frac{\text { Pengaruh tidak langsung }}{\text { Pengaruh total }}
$$

Hasil pengujian $\mathrm{H} 4$ pada Tabel 5 mengenai uji hipotesis pengaruh tidak langsung, terlihat bahwa nilai VAF sebesar $61,6 \%$. Pedoman untuk kriteria yang digunakan: VAF $>70 \%$ maka disebut pemediasi penuh (full mediation); VAF memiliki nilai $>20 \%-<70 \%$, maka disebut pemediasi parsial. VAF pada hipotesis $4(\mathrm{H} 4)$ sebesar $61,6 \%$ tergolong partial mediation.

Hasil uji $\mathrm{H} 4$ sejalan dengan penelitian Alomary dan Woollard (2015), menyatakan kemudahan penggunaan berpengaruh terhadap niat untuk menggunakan. PU mempengaruhi niat pengguna untuk menerapkan teknologi (Rahmawati \& Narsa, 2019). Ducey dan Coovert (2016) menyebutkan sikap pengguna dapat menentukan niat untuk mengadopsi teknologi, seperti PEU dan PU. 
Hasil uji H5 pada Tabel 5 mengenai uji hipotesis pengaruh tidak langsung, terlihat bahwa nilai VAF sebesar 41,0197\%. Pedoman untuk kriteria yang digunakan: VAF $>70 \%$ maka disebut pemediasi penuh (full mediation); VAF memiliki nilai $>20 \%$ $<70 \%$, maka disebut pemediasi parsial. VAF pada hipotesis 5 (H5) sebesar 41,0197\% termasuk dalam kategori pemediasi parsial. Hasil pengujian dari hipotesis 5 (H5), sejalan dengan Ducey dan Coovert (2016), dimana niat mengadopsi teknologi ditentukan dari sikap pengguna, seperti PEU dan PU. Ducey dan Coovert (2016) menunjukkan bahwa niatan untuk menggunakan dipengaruhi positif oleh PEU dan PU.

\section{Simpulan}

Penelitian tentang penggabungan teknologi dengan metode pengajaran dalam pendidikan formal telah mengalami proses evolusi. Salah satu metode CSCL dimana memfokuskan pemakaian komputer sebagai alat bantu diantaranya yaitu metode belajar dengan e-learning. Selain kebermanfaatan yang dirasakan dari penggunaan $e$ learning, tidak akan menjadi suatu halangan bila mahasiswa mempunyai keinginan yang kuat untuk memanfaatkan teknologi ini. Segala sesuatunya mampu dipelajari secara mudah dan cepat jika pengguna berkeinginan kuat untuk menggunakan e-learning. Berdasarkan hasil analisis data, perceived usefulness tidak berpengaruh signifikan pada actual usage. Sementara itu percieved usefulness berpengaruh signifikan pada ITU serta actual usage yang dimediasi oleh ITU. Intention to use sebagai mediator antara perceived usefulness dengan actual usage termasuk dalam kategori pemediasi parsial. PEU berpengaruh signifikan pada intention to use, serta ketika actual usage dimediasi oleh intention to use. Selain itu, intention to use memiliki pengaruh ke actual usage.

Hasil membuktikan bahwa PU dan PEU secara langsung tidak dapat menentukan pengguna dalam penerapan $e$ learning. Adanya kemudahan dalam im- plementasi teknologi dan sistem dapat dijadikan sebagai salah satu dorongan untuk mahasiswa agar lebih intens dalam penggunaan e-learning yang dibuat oleh pihak universitas. Selain itu, peran pengajar atau dosen juga dapat memotivasi mahasiswa agar lebih sering mengakses elearning. Penelitian ini memberi kontribusi terhadap fenomena dalam konteks pendidikan, terutama dalam penerapan sistem informasi.

Penelitian ini hanya dilakukan di Universitas Airlangga. Untuk penelitian selanjutnya dapat dilakukan komparasi dengan universitas atau perguruan tinggi lain yang memiliki e-learning. Penelitian lebih lanjut juga dapat melakukan evaluasi terhadap penggunaan e-learning. Adanya fasilitas e-learning yang disediakan oleh pihak universitas seharusnya dapat lebih dimanfaatkan lagi sebagai penunjang kegiatan belajar. Namun masih belum banyak yang memanfaatkan dengan baik. Banyak faktor lain yang dapat mempengaruhi penggunaan e-learning, seperti: peran dosen sebagai pengajar di kelas, IT, dan masih banyak faktor lain. Penelitian yang akan datang dapat menambah variabel yang berhubungan.

Implikasi penelitian ini dapat dijadikan sebagai evaluasi dan pembelajaran agar lebih baik lagi kedepannya untuk menerapkan e-learning di Universitas Airlangga. Untuk beberapa materi kelas yang belum menggunakan e-learning, dapat dilakukan uji coba sebagai pengenalan terhadap mahasiswa. AULA merupakan portal $e$ learning di Universitas Airlangga. Pengenalan terhadap AULA (Airlangga Univeristy e-learning Application) ini juga dapat dilakukan melalui sosialisasi ataupun pelatihan kepada pengajar dan mahasiswa agar penggunaannya dapat lebih maksimal.

\section{Daftar Pustaka}

Al-Azawei, A., Patrick, P., \& Lundqvist, K. (2017). Investigating the effect of learning styles in a blended e-learning system: an extension of the 
Technology Acceptance Model (TAM). Australasian Journal of Educational Technology, 33(2), 1-23. doi:https//doi.org/10.14742/ajet.2758.

Alomary, A., \& Woollard, J. (2015, 21st November 2015). How is Technology Accepted by Users? A Review of Technology Acceptance Models and Theories. The IRES - 17th International Conference, London, United Kingdom.

Baleghi -Zadeh, S., Ayub, A. F. M., Mahmud, R., \& Daud, S. M. (2017). The Influence of System Interactivity and Technical Support on Learning Management System Utilization. Knowledge Management \& Elearning: An International Journal, 9(1), 50-68. doi:https://doi.org/10.34105/j.kmel.20 17.09.004.

Barhoumi, C. (2016). User acceptance of the e-Information service as information resource: a new extension of the technology acceptance model. New Library World, 117(9/10), 626643. doi:https//doi.org/10.1108/NLW06-2016-0045.

Baziad, M. (2015). Digital economy Indonesia aims to beat Malaysia in internet. Retrieved from https://www.digitalnewsasia.com/digit al-economy/indonesia-aims-to-beatmalaysiaininternet.

Cakır, R., \& Solak, E. (2015). Attitude of Turkish EFL learners towards $e$ learning through TAM model. Procedia - Social and Behavioral Sciences, 176, 596-601. doi:https://doi.org/10.1016/j.sbspro.20 15.01.515.

Chang, I.-C., Li, Y.-C., Hung, W.-F., \& Hwang, H.-G. (2005). An empirical study on the impact of quality antecedents on tax payers' acceptance of internet tax-filing systems. Government Information Quarterly,
22(3), 389-410.

doi:https://doi.org/10.1016/j.giq.2005. 05.002 .

Davis, F. D. (1985). A technology acceptance model for empirically testing new end-user information systems: theory and results. (Ph.D in Management Disertation), Massachusetts Institute of Technology, Sloan School of Management.

Davis, F. D. (1989). Perceived usefulness, perceived ease of use, and user acceptance of information Technology. MIS Quarterly, 13(3), 319-340. doi:https//doi.org/10.2307/249008.

Ducey, A. J., dan Coovert, M. D. (2016). Predicting Tablet Computer Use: An Extended Technology Acceptance Model for Physicians. Health Policy and Technology, 5(3), 268-284. doi: https://doi.org/10.1016/j.hlpt.2016.03. 010

Fadare, O. (2015). A survey on perceived risk and intention of adopting internet banking. The Journal of Internet Banking and Commerce, 21(1), 1-21.

Folden, R. W. (2012). General perspective in learning management systems. Higher education institutions and learning management systems: Adoption and Standardization (pp. 127): IGI Global. doi:https//doi.org/10.4018/978-160960-884-2.ch001

Handayani, W. P. P., \& Harsono, M. (2016). Aplikasi Technology Acceptance Model (TAM) pada komputerisasi kegiatan pertanahan. Jurnal Economia, 12(1), 13-22. doi:https://doi.org/10.21831/economia. v12i1.8415.

Harris, I. (2017). Analisis Technology Acceptance Model (TAM) terhadap tingkat penelrimaan e-learning pada kalangan mahasiswa (Studi empiris pada Universitas Internasional Batam 
dan UPBJJ-UT Batam). Jurnal

Terapan Manajemen dan Bisnis, 3(1), 1-20.

Hussein, Z. (2017). Leading to intention: the role of attitude in relation to Technology Acceptance Model in $e$ learning. Procedia Computer Science, 105, 159-164. doi:https://doi.org/10.1016/j.procs.201 7.01.196.

Jogiyanto, H. M. (2008). Metodologi penelitian sistem informasi. Yogyakarta: Penerbit Andi.

Khan, A., \& Woosley, J. M. (2019). Comparison of contemporary Technology Acceptance Models and evaluation of the best fit for health industry organizations. International Journal of Computer Science \& Engineering Technology, 1(1), 709717.

Kusmana, A. (2017). E-learning dalam pembelajaran. Lentera Pendidikan: Jurnal Ilmu Tarbiyah dan Keguruan, 14(1), 35-51.

doi:https://doi.org/10.24252/lp.2011v1 4n1a3.

Nursiah, N. (2018). Pengaruh perceived ease of use dan perceived usefulness terhadap behavior intention to use. Jurnal Elektronik Sistem Informasi dan Komputer, 3(2), 39-47.

Priyadi, I. P., Nugraha, H. C., Ratih, C. K., Nugroho, H. A., Karyana, K., Reinaldo, R. N., ... Subiyantoro, E. (2013). Simulasi Digital Jilid 1. Jakarta: Kementrian Pendidikan \& Kebudayaan.

Rahmawati, R. N., \& Narsa, I. M. (2019). Intention to use e-learning: aplikasi Technology Acceptance Model (TAM). Owner, 3(2), 260-269. doi:https://doi.org/10.33395/owner.v3i 2.151 .

Sánchez-Prieto, J. C., Olmos-Migueláñez, S., \& García-Peñalvo, F. J. (2017). MLearning and pre-service teachers: an assessment of the behavioral intention using an expanded TAM model. Computers in Human Behavior, 72, 644-654. doi:https://doi.org/10.1016/j.chb.2016. 09.061 .

Setiawan, W., Hana, M. N., \& Waslaludin, W. (2014). Analisis penerapan sistem e-learning FPMIPA UPI menggunakan Technology Acceptance Model (TAM). Jurnal Pengajaran MIPA, 19(1), 128-140. doi:http://dx.doi.org/10.18269/jpmipa. v19i1.433.

Silva, J. R., Silva, A. F. d., \& Chan, B. L. (2019). Enterprise risk management and firm value: evidence from Brazil. emerging markets finance and trade, 55(3), 687-703.

doi:https://doi.org/10.1080/1540496X 2018.1460723.

Smet, C. D., Bourgonjon, J., Wever, B. D., Schellens, T., \& Valcke, M. (2012). Researching instructional use and the technology acceptation of learning management systems by secondary school teachers. Computers \& Education, 58(2), 688-696. doi:https://doi.org/10.1016/j.compedu. 2011.09.013.

Wang, Q. (2009). Design and evaluation of a collaborative learning environment. Computers \& Education, 53(4), 11381146. doi:https://doi.org/10.1016/j.compedu. 2009.05.023. 